International Journal of Current Advanced Research

ISSN: O: 2319-6475, ISSN: P: 2319 - 6505, Impact Factor: SJIF: 5.995

Available Online at www.journalijcar.org

Volume 6; Issue 5; May 2017; Page No. 3719-3721

DOI: http://dx.doi.org/10.24327/ijcar.2017.3721.0354

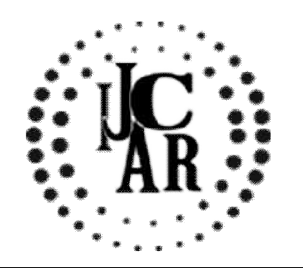

Research Article

\title{
KNOWLEDGE AND AWARENESS REGARDING THE USE OF CHLORHEXIDENE MOUTHWASH AMONG THE DENTAL STUDENTS
}

\author{
Abhishek $\mathbf{N}$ and Jayalakshmi
}

Saveetha Dental College and Hospitals 162 Poonamalle High road Chennai 600077

\section{A R T I C L E I N F O}

\section{Article History:}

Received $19^{\text {th }}$ February, 2017

Received in revised form $13^{\text {th }}$ March, 2017

Accepted $24^{\text {th }}$ April, 2017

Published online $28^{\text {th }}$ May, 2017

\section{Key words:}

Mouthwash, Chlorhexidine, Triclosan, Listerine, Burning Mouth Syndrome

\begin{abstract}
A B S T R A C T
Aim and Objective: to evaluate the knowledge and Awareness regarding the use of chlorhexidene mouthwash in dental students

Materials and methods: This study was conducted online through Survey planet link. A total of 100 respondents had completed this survey. The questionnaire has 10 multiple choice questions. The age of the respondents involved in this survey are in range between 18 years old to 25 years old.

Results: majority of the respondents said they use chlorhexidine mouthwash occasionally.and considerable number of respondents said they use mouthwash majority if the respondents selected discoloration of the teeth as the major disadvantage of chlorhexidine mouthwash. Majority of the students said burning sensation as the major disadvantage of listerine. Majority of the respondents said hormonal problems as major disadvantage of triclosan and $98 \%$ of the respondents said they need more awareness programs about in detail usage of mouthwash.
\end{abstract}

Reason: To evaluate if the dental students have sufficient knowledge about usage and side effects of chlorhexidene mouthwash

Copyright $₫ 2017$ Abhishek $\mathbf{N}$ and Jayalakshmi. This is an open access article distributed under the Creative Commons Attribution License, which permits unrestricted use, distribution, and reproduction in any medium, provided the original work is properly cited.

\section{INTRODUCTION}

A mouthwash is a solution which is used to rinse away food particles and plaque from the teeth. It is used after brushing the teeth and can form part of a daily oral care routine. Mouth rinses are used for a variety of reasons to freshen breath, to help prevent or control tooth decay, to reduce plaque, to prevent or reduce gingivitis to reduce the speed that tartar forms on the teeth, or to produce a combination of these effects. Active ingredients in mouthwash can include thymol, eucalyptol, hexetidine, methyl salicylate, menthol, chlorhexidine gluconate, benzalkonium chloride, cetylpyridinium chloride, methylparaben, hydrogen peroxide, domiphen bromide and sometimes uoride, enzymes and calcium. Ingredients also include water, sweeteners such as sorbitol, sucralose, sodium saccharine, and xylitol. The indications of mouthwashes include: in the treatment of gingivitis, periodontitis, halitosis and in the maintenance of oral hygiene, particularly following periodontal surgery. The most commonly used mouthwash are chlorhexidine, listerine, and triclosan Chlorhexidene is the gold standard mouthwash.It is known for its an antimicrobial effect. It acts on the inner cytoplasmic membrane hence it is a membrane

*Corresponding author: Abhishek N

Saveetha Dental College and Hospitals 162 Poonamalle High road Chennai 600077 active type of substance. It prevents plaque accumulation; hence it is an antiplaque and antigingivitisagent and reduces the adherence of Porphyromonas gingivalis to epithelial cells. It is effective against all the microbes against viruses and fungi also. Although many products have been used to control plaque and gingivitis, chlorhexidene is one of the most widely used anti septics.The major advantages of chlorhexidene over other product is its substantivity, it binds to soft and hard tissues in the mouth enabling it to act for a longer period. It can be bacteriostatic or bactericidal depending on the dose. Listerine is a mixture of three phenolic-derived essential oils--thymol, menthol and eucalyptol--combined with methyl salicylate. The mechanism of action appears to be related to alteration of the bacterial cell wall. This product is uncharged and has a low substantivity.

Triclosan is a chemical used as a preservative as well as to kill or remove bacteria in various products. Products include soaps, natural health products, body washes, shower gels and shampoos, non-prescription drugs such as toothpaste, mouthwash and hand sanitizer

\section{MATERIALS AND METHODS}

This study was conducted online through Survey planet link. The survey consists of 10 multiple -choice questions regarding the use and disadvantages of mouthwash among 
dental students in a dental school. A total of 100 respondents had completed this survey. The age of the respondents involved in this survey are in range between 18 years old to 25 years old. Based on the answers provided by the respondents, result was gained to the conclusion and analysis was made by using pie charts for each and every question

\section{Which mouthwash do you use}

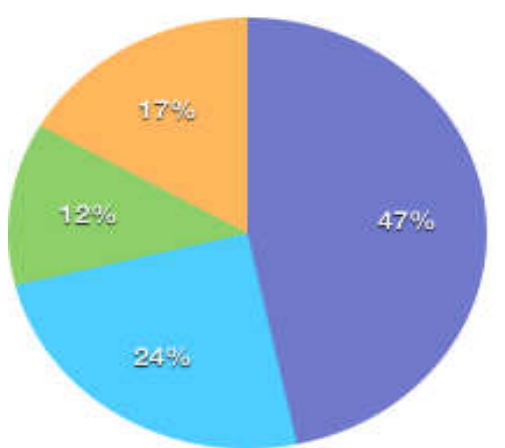

- Chiorhexidine

Listerine

Triciosan

Herbal
How frequently do you use mouthwash

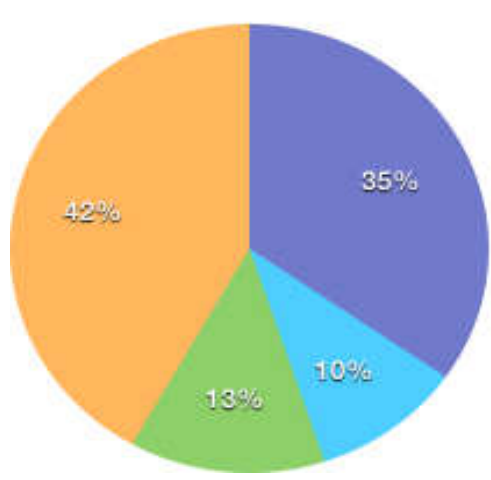

- Once in a Day Twice in a day Weekly

Occasionally
Are you aware about the disadvantages of chlorhexidene mouthwash if yes list out the disadvantages

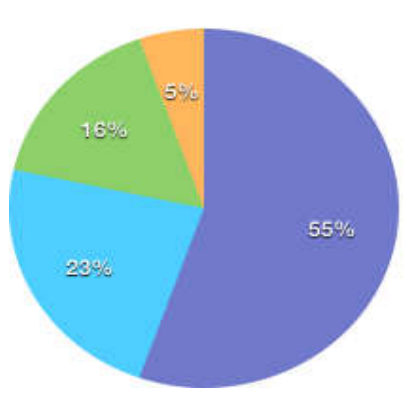

Reversible desquamation in children Increased supra gingival calculus Don't know

Are you aware about the disadvantages of listerine mouthwash if yes list out?

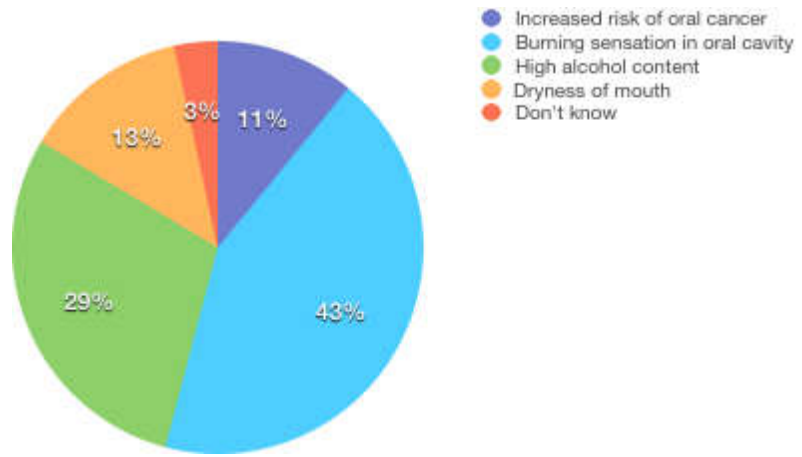

Are you aware about the disadvantages of triclosan mouthwash if yes list out

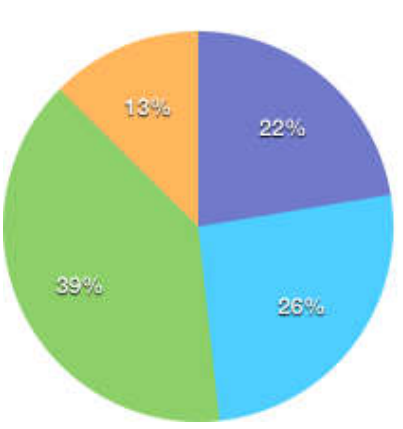

Endocrine disruption

Increased risk of allergies in children

Don't to hamonal problerns

Have you heard of mouthwash overdose in children if yes mention the symptoms?

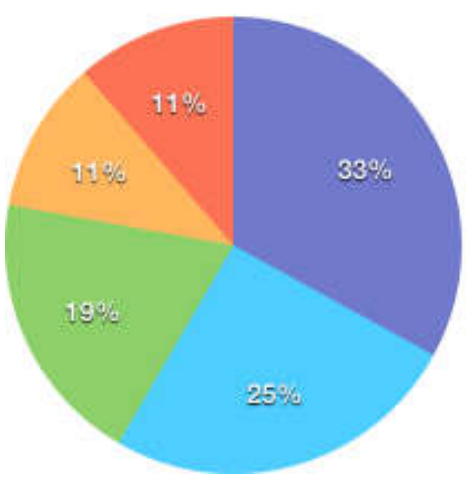

Diarrhea

Low body temperature

Nausea and vomiting

Coma

- Dan't know

Which mouthwash causes alteration in taste sensation?

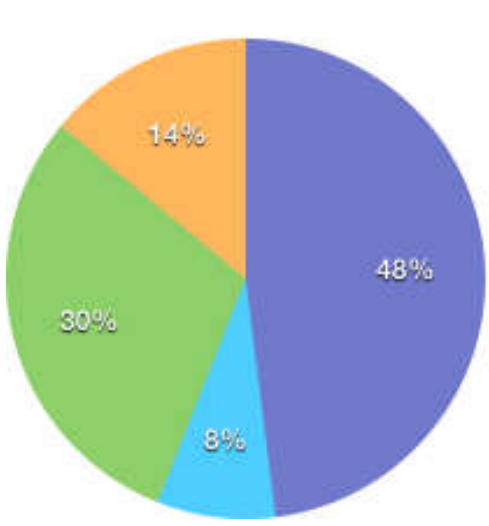

Listerine

Triclosan

Chiorhexidine

Don't know

Which mouthwash do you prefer for patient suffering from burning mouth Syndrome

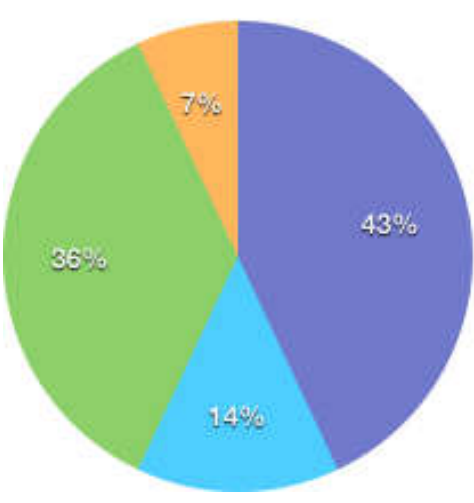

Chlorhexidine

Herbal mouthwash

Flouride mouthwash

Don't know 
Do You Think There Is A Need For More Awareness Programs About Indetail Usage Of The Mouthwash Yes No

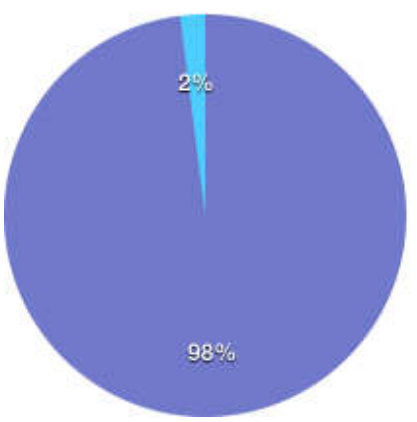

\section{DISCUSSION}

Continued use of products containing chlorhexidine for long periods can cause stains on teeth, tongue, and gingiva, also on silicate and resin restorations; prolonged use can also reduce bitter and salty taste sensations - this latter symptom can be reversed by ceasing use of chlorhexidine.[1] The brownish discoloration of teeth and tongue is due to the disintegration of bacterial membranes, leading to the denaturation of bacterial proteins.[2] Triclosan has been associated with a higher risk of food allergy.[3]. A Toxicological Sciences study found that triclosan affected estrogen-mediated responses, and many chemicals that imitate estrogen are known to increase breast cancer risk.Triclosan also suppressed thyroid hormone in rats, and this is only one study in an accumulating body of research showing this chemical to be a potent endocrine disrupter.[4] The use of alcoholcontaining mouthwash such as Listerine may increase the risk of developing oral cancer.[5]. When ingested in large quantities, the phenolic compounds in mouthwash may contribute to a severe anion-gap metabolic acidosis and osmolar gap, multiorgan system failure, and death. These compounds, in addition to alcohol, may account for the adverse effects associated with massive mouthwash ingestion.[6]

\section{CONCLUSION}

From the results it is concluded that the knowledge about the usage of the various mouthwashes is very low. 98 out of the 100 participants said that there is a need for usage of the mouthwash so there is a need for more programs to create awareness and provide knowledge about the usage of the mouthwash among the people for good oral care and a healthy community.

\section{Reference}

1. Helms JA, Della-Fera MA, Mott AE, Frank ME (October 1995). "Effects of chlorhexidine on human taste perception". Arch. Oral Biol. 40 (10): 913-20.

2. Hjeljord LG, Rolla G, Bonesvoll P (1973). "Chlorhexidine-protein interactions". J Periodontal Res Suppl. 12: 11-6.

3. Sicherer, Scott H.; Leung, Donald Y.M. (2013). "Advances in allergic skin disease, anaphylaxis, and hypersensitivity reactions to foods, drugs, and insects in 2012". Journal of Allergy and Clinical Immunology. 131 (1): 55-66.

4. Triclosan Exposure Modulates Estrogen-Dependent Responses in the Female Wistar Rat Tammy E. Stoker*,1, Emily K. Gibson* and Leah M. Zorrilla*†

5. $\wedge$ McCullough, Michael; C. S. Farah (December 2008). "The role of alcohol in oral carcinogenesis with particular reference to alcohol-containing mouthwashes". Australian Dental Journal. 53 (4): 302305.

6. Jothika M, Vanajassun $\mathrm{P} P$, Someshwar B. Effectiveness of probiotic, chlorhexidine and fluoride mouthwash against Streptococcus mutans Randomized, single-blind, in vivo study. J Int Soc Prevent Communit Dent 2015;5, Suppl S1:44-8

\section{How to cite this article:}

Abhishek N and Jayalakshmi (2017) 'Knowledge And Awareness Regarding The Use Of Chlorhexidene Mouthwash Among The Dental Students', International Journal of Current Advanced Research, 06(05), pp. 3719-3721.

DOI: http://dx.doi.org/10.24327/ijcar.2017.3721.0354 